Regular Paper

\title{
A Battery Charging System for Intermittent Generation from a Synchronous Generator with a Novel Maximum Power Point Tracking Control
}

\author{
S. IMAMOTO ${ }^{* 1}$, H. YAMADA $^{* 2}$, T. HANAMOTO ${ }^{* 1}$, Y. SHIRAI $^{* 1}$ and M. NORHISAM ${ }^{* 3}$
}

\begin{abstract}
This paper proposed a battery charging system for intermittent generation from a synchronous generator with a novel Maximum Power Point Tracking (MPPT) control method. Analyzing the generation with boost chopper by the state space averaging method, the internal voltage of the generator, the output voltage and the resistance of the output of the boost chopper can be estimated by with only single current sensor. Even though the intermittent generation, the proposed the battery charging system is able to charge the battery constantly because of a bi-directional DC/DC converter and an Electric Double-Layer Capacitor (EDLC). The basic principle of the proposed MPPT control method and the proposed charging system are discussed, and then confirmed by digital computer simulation using PLECS. The simulation results reveal that the proposed MPPT controller controls the maximum power point and the proposed charging system is able to charge the battery constantly.
\end{abstract}

Keywords: MPPT, state space averaging method, boost chopper, intermittent generator, and synchronous generator. (Received: 24 July 2014, Revised: 30 April 2015)

\section{Introduction}

Malaysia has a $42.8 \%$ share of the world palm oil industry [1]. Palm oil is one of plant oils such as soy and colza. The oil palm fruits are transferred to steam boiler to remove the husk in the milling process. The considerable quantities of steam are used in extracting palm oil. These steam energy is released to the air. The focus of this research utilizes this wasted energy.

The release pattern of the steam is intermittent. In general, Permanent Magnet Synchronous Generators (SGs) [2-4] are used for wind power generation. However, the maximum power point of SGs changes with the rotating speed of the turbines. Conventional maximum power point tracking (MPPT) control methods have been proposed using the hill-climbing method and the angle and current feedback method [5]. The hillclimbing method is to seek the maximum power point by calculating the generated power with a voltage and current sensors. The angle and current feedback method is to adjust the maximum power point by using the three sensors' information. However these methods need two or three sensors.

This paper proposes a battery charging system for intermittent generation from a synchronous generator with novel maximum power point tracking control. The charged battery is used in the agricultural equipment during the harvesting process. Analyzing the boost chopper for maximizing the generated power by the

\footnotetext{
Correspondence: H. YAMADA, Graduate School of Science and Engineering, Yamaguchi University, 2-16-1, Tokiwadai, Ube, Yamaguchi, 755-8611, Japan email: hiro-ymd@yamaguchi-u.ac.jp

${ }^{* 1}$ Kyushu Institute of Technology ${ }^{* 2}$ Yamaguchi University ${ }^{* 3}$ Universiti Putra Malaysia
}

state space averaging method, the internal voltage of the generator and the output voltage of the output of the boost chopper can be estimated by with only single current sensor. In intermittent period, the SG doesn't generate the power and the battery cannot charge. The bi-directional DC/DC converter and an Electric DoubleLayer Capacitor (EDLC) is used for charging the battery constantly in every period [6].

Digital computer simulation is implemented to confirm the validity of the proposed method by using PLECS software. The results reveal that the proposed MPPT controller tracks the maximum power point and the proposed charging system is able to charge the battery constantly.

\section{Characteristics of the Synchronous generator}

The test circuit consists of the SG, a diode rectifier, smoothing capacitor and resistor. Fig. 1 shows the V-I characteristic of the SG in this paper. The voltage and current of the SG increases with the rotation speed. Fig. 2 shows the V-P characteristic of the SG. From Fig. 2, the maximum power point voltage is changed with the rotation speed. From these characteristics, the internal resistance of the $\mathrm{SG}$ around the maximum power point is $16.0 \Omega$.

The SG is modelled to demonstrate the characteristics on the digital computer simulation. The SG with the diode rectifier can replace the voltage source with the internal resistor. The approximated value of the voltage source is given as follows

$$
\begin{aligned}
v_{M}= & \left(-0.0024^{*} w+1.6041\right)^{*} i_{R e c}{ }^{2}+\left(0.0066^{*} w\right. \\
& -15.712)^{*} i_{R e c}+0.0563^{*} w+9.757
\end{aligned},
$$




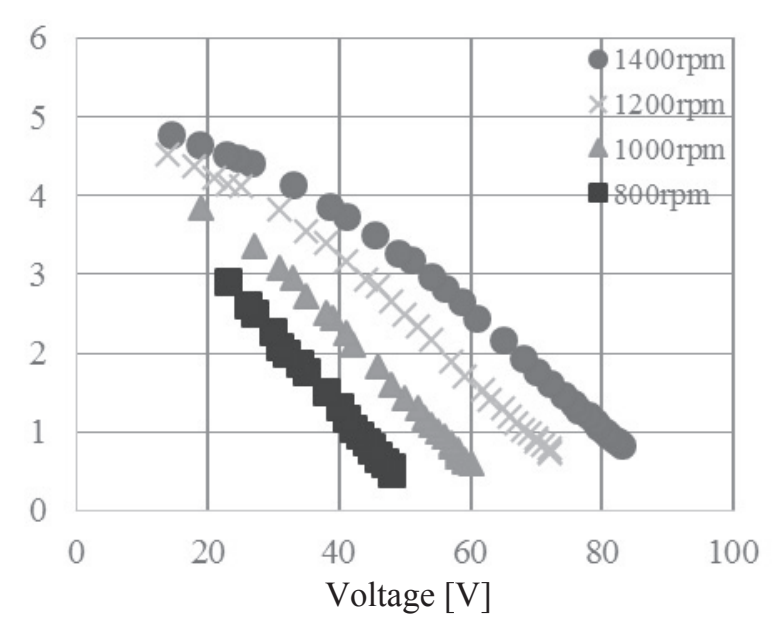

Fig. 1. V-I characteristic of the SG

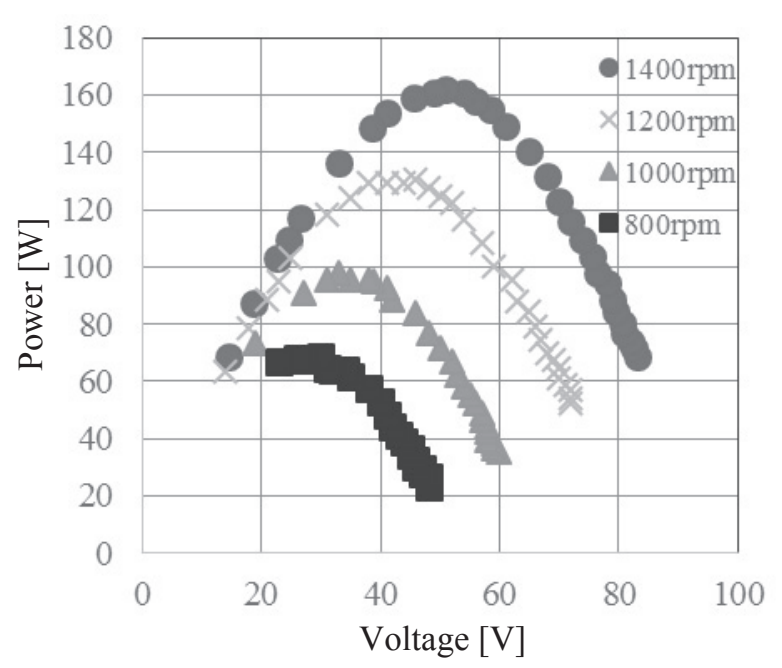

Fig. 2. V-P characteristic of the SG

where $w$ is the rotating speed [rpm] and $i_{R e c}$ is the current value of diode rectifier. When the value of the rotating speed is small, the forward voltage of the diode rectifier is large to the rectified voltage because the generating voltage is small. However, the characteristics of SG include this nonlinear property. Therefore the accuracy of equation (1) is enough to analyze the proposed system.

\section{System configuration}

Fig. 3 shows a power circuit diagram of the proposed battery charging system. The proposed system consists of the turbine, SG, boost chopper, step-down chopper and bi-directional DC/DC converter. The generated power tracks the maximum power point using a boost chopper with the proposed MPPT control. The proposed MPPT controller uses only one sensor because the estimator estimates the terminal voltage $v_{T}$ of $C_{\text {Rec }}$. The battery is demonstrated as a resistor $R_{B}$ in this paper. A step-down chopper is used for charging the battery.

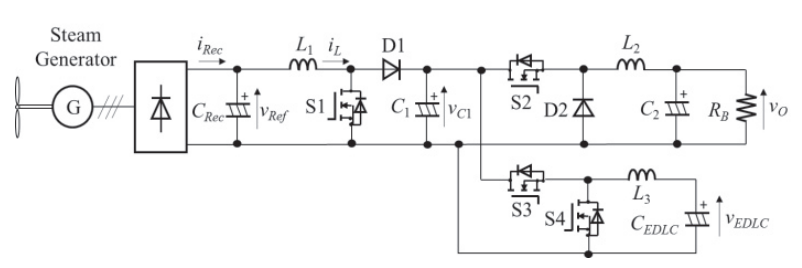

Fig. 3. A power circuit diagram of the proposed battery charging system.

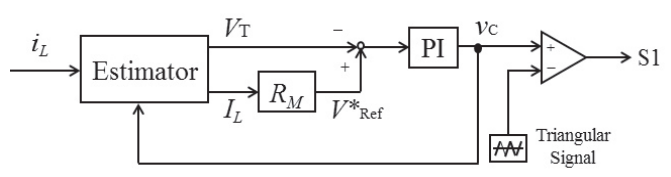

(a) MPPT control block.

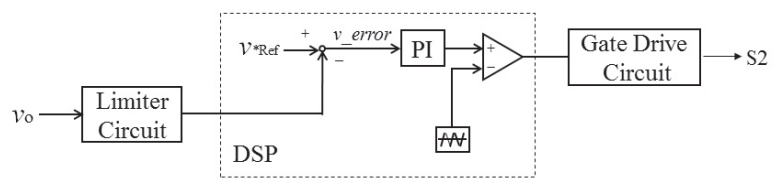

(b) Charge voltage control for a battery
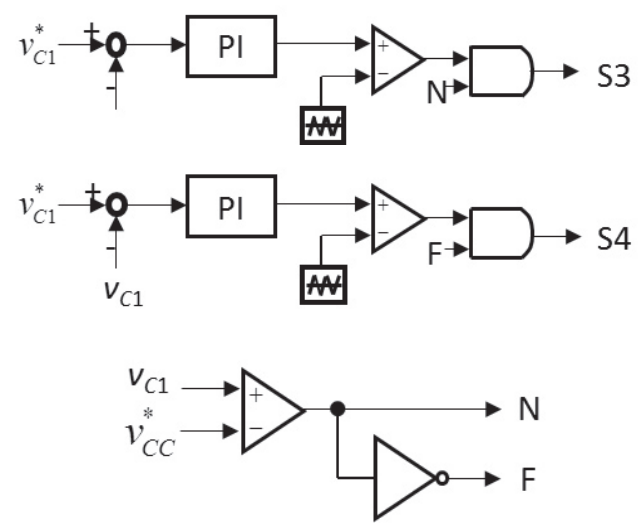

(c) DC link voltage control

Fig. 4. A block diagram of Fig. 3

The generated power of the SG is discontinuous because of the intermittent working cycles of the steam. The electric double-layer capacitor $C_{E D L C}$ is charged from the surplus power using a bi-directional DC/DC converter in the generating mode. In the non-generating mode, the bi-directional DC/DC converter acts as a boost chopper for charging the battery. The bi-directional DC/DC converter keeps the DC link voltage. Thus, the battery is charged constantly.

Fig. 4 shows a block diagram of Fig. 3. Fig. 4 (a) shows the MPPT control block. In section 4, the MPPT control method is described in detail. Fig. 4 (b) shows the charge voltage control for a battery. Fig. 4 (c) shows the DC link voltage control. The bidirectional DC/DC converter switches over by the generating and nongenerating modes. $v_{\mathrm{cc}}^{*}$ is the reference value for switching over. 


\section{Proposed MPPT control method}

Fig. 5 shows the basic system configuration of the steam generation system. The resistor $R_{O}$ demonstrates the equivalent resistance of the step-down chopper and

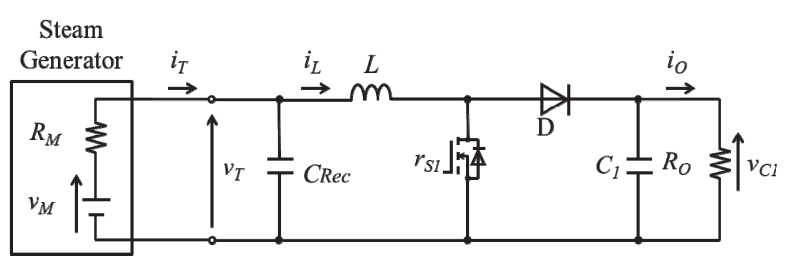

Fig. 5. System configuration of the steam generation system using a boost chopper

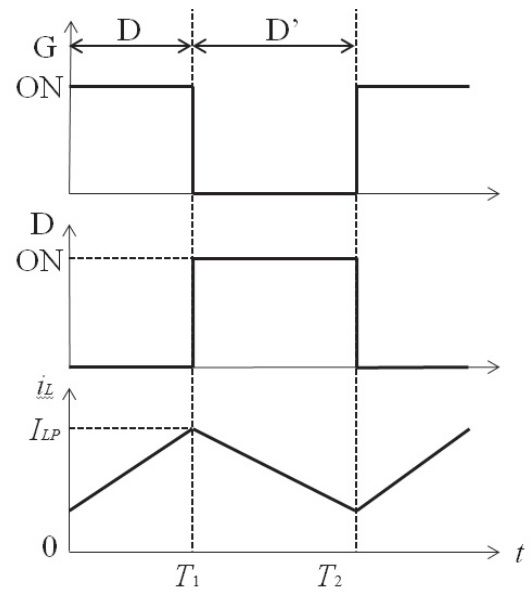

Fig. 6. Relationship between the switching condition and $i_{L}$

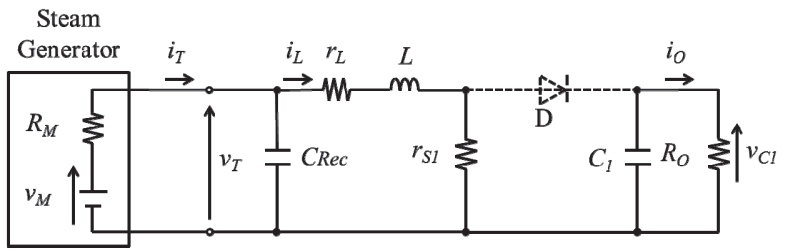

Fig. 7. Equivalent circuit of the steam generation system during.(MODE 1)

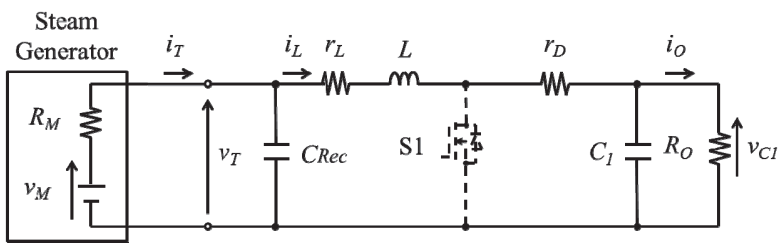

Fig. 8. Equivalent circuit of the steam generation system (MODE 2) bi-directional DC/DC converter. The boost chopper harvests the generated power at the maximum power point. The input and output side of the boost chopper is connected the smoothing capacitors.

\subsection{Analyzing the steam generation system}

This section reveals that the output of the steam generation can estimate by using the linear analyzing result of the system. This paper uses the state space averaging method [7], [8] for this analyzing the boost chopper.

The boost chopper acts in continuous current mode (CCM). There are two modes in CCM. Fig. 6 shows the relationship between switching condition and $i_{L}$. D is the duty ratio during $\mathrm{S} 1$-on period and $\mathrm{D}^{\prime}$ is the duty ratio during S1-off period. Thus, we analyze the two modes. The state equations of Fig. 7 and Fig. 8 set up where the state variable $x$ is $\left(v_{T} i_{L} v_{C I}\right) T$.

Fig. 7 illustrates the equivalent circuit during $\mathrm{G}$ is ON. During $G$ is $O N, i_{L}$ increases from 0 to the peak value $I_{L P} . r_{S I}$ is the ON-resistance of the switch $\mathrm{S} 1$, and $r_{L}$ is the winding resistance of $L$. From Fig. 5, the state equation of the MODE 1 is given as follows

$$
\begin{gathered}
\frac{d v_{T}}{d_{t}}=\frac{v_{M}}{R_{M} C_{R e c}}-\frac{i_{L}}{C_{R e c}}-\frac{v_{T}}{R_{M} C_{R e c}} \\
\frac{d i_{L}}{d_{t}}=\frac{v_{T}}{L}-\frac{r_{L}+r_{S}}{L} i_{L}, \\
\frac{d v_{C 1}}{d_{t}}=-\frac{v_{C 1}}{R_{O} C_{R e c}} .
\end{gathered}
$$

From these equations, the matrix is given by

$$
\frac{d x}{d_{t}}=\boldsymbol{A}_{1} x+\boldsymbol{b}_{1} v_{M}
$$

where $A_{1}$ and $b_{1}$ are given by

$$
\boldsymbol{A}_{1}=\left[\begin{array}{ccc}
-\frac{1}{R_{M} C_{R e c}} & -\frac{1}{C_{R e c}} & 0 \\
\frac{1}{L} & \frac{r_{L}+r_{S}}{L} & 0 \\
0 & 0 & -\frac{1}{R_{O} C_{1}}
\end{array}\right],
$$

Fig. 8 illustrates the equivalent circuit during $G$ is OFF. $r_{D}$ is the conduction resistance of $D$. From Fig. 8, the state equation of the MODE 2 is given as follows 


$$
\begin{gathered}
\frac{d v_{T}}{d_{t}}=\frac{v_{M}}{R_{M} C_{R e c}}-\frac{i_{L}}{C_{R e c}}-\frac{v_{T}}{R_{M} C_{R e c}}, \\
\frac{d i_{L}}{d_{t}}=\frac{v_{T}}{L}-\frac{v_{C 1}}{L}-\frac{r_{L}+r_{D}}{L} i_{L}, \\
\frac{d v_{C 1}}{d_{t}}=-\frac{v_{C 1}}{R_{O} C_{1}}+\frac{i_{L}}{C_{1}} .
\end{gathered}
$$

From these equations, the matrix is given by

$$
\frac{d \overline{\boldsymbol{x}}}{d_{t}}=\boldsymbol{A}_{2} x+\boldsymbol{b}_{2} v_{M},
$$

where $\boldsymbol{A}_{2}$ and $\boldsymbol{b}_{2}$ are given by

$$
\begin{gathered}
\boldsymbol{A}_{2}=\left[\begin{array}{ccc}
-\frac{1}{R_{M} C_{R e c}} & -\frac{1}{C_{R e c}} & 0 \\
\frac{1}{L} & \frac{r_{L}+r_{D}}{L} & -\frac{1}{L} \\
0 & \frac{1}{C_{1}} & -\frac{1}{R_{O} C_{1}}
\end{array}\right], \\
\boldsymbol{b}_{2}=\left[\begin{array}{c}
\frac{1}{R_{M} C_{R e c}} \\
0 \\
0
\end{array}\right]
\end{gathered}
$$

The state averaging equation is assumed as follows

$$
\overline{\boldsymbol{x}}=\left(\bar{v}_{T} \bar{i}_{L} \bar{v}_{C 1}\right) T .
$$

The state averaging equation can be derived as

$$
\begin{aligned}
& \frac{d \overline{\boldsymbol{x}}}{d_{t}}=\boldsymbol{A} \overline{\boldsymbol{x}}+\boldsymbol{b} V_{M}, \\
& \boldsymbol{A}=D \boldsymbol{A}_{1}+D^{\prime} \boldsymbol{A}_{2} \\
& =\left[\begin{array}{ccc}
-\frac{1}{R_{M} C_{R e c}} & -\frac{1}{C_{R e c}} & 0 \\
\frac{1}{L} & -\frac{r}{L} & -\frac{D^{\prime}}{L} \\
0 & \frac{D^{\prime}}{C_{1}} & -\frac{1}{R_{O} C_{1}}
\end{array}\right], \\
& \boldsymbol{b}=D \boldsymbol{b}_{1}+D^{\prime} \boldsymbol{b}_{2} \\
& =\left[\begin{array}{c}
\frac{1}{R_{M} C_{R e c}} \\
0 \\
0
\end{array}\right],
\end{aligned}
$$

$$
r=D r_{S}+D^{\prime} r_{D}+r_{L}
$$

The following equation can be written in the steady state

$$
\frac{d \overline{\boldsymbol{x}}}{d_{t}}=\mathbf{0} .
$$

Therefore $V_{T}, I_{L}$ and $V_{C 1}$ in the steady state can be derived as

$$
\left[\begin{array}{c}
V_{T} \\
I_{L} \\
V_{C 1}
\end{array}\right]=\frac{V_{M}}{r+R_{O} D^{\prime 2}+R_{M}}\left[\begin{array}{c}
r+R_{O} D^{\prime 2} \\
1 \\
R_{O} D^{\prime}
\end{array}\right] .
$$

The average value $I_{L}$ of $i_{L}$ is given as follows

$$
I_{L}=\frac{1}{r+R_{O} D^{\prime 2}+R_{M}} V_{M} .
$$

The internal voltage $V_{M}$ of the steam generator is given by

$$
V_{M}=\left(D r_{S 1}+D^{\prime} r_{D 1}+r_{L 1}+R_{O} D^{\prime 2}+R_{M}\right) I_{L} .
$$

The rectified voltage $V_{T}$ can be expressed as

$$
V_{T}=\left(D r_{S}+D^{\prime} r_{D}+r_{L}+R_{O} D_{M}^{\prime 2}\right) I_{L}
$$

The output of the boost chopper $R_{O}$ can be derived as

$$
R_{O}=\frac{V_{C 1}}{D^{\prime} I_{L}} .
$$

Therefore, $V_{M}, V_{T}$ and $R_{O}$ can be estimated by detecting only the inductor current $i_{L}$.

\subsection{Proposed MPPT control method}

From the analysis result in Section 4.1, $V_{T}$ and $V_{M}$ can be estimated by the inductor current. Fig. 9 shows the circuit diagram using the proposed MPPT control method. $I_{T}$ is given by

$$
I_{T}=\frac{V_{M}-V_{T}}{R_{M}} .
$$

$V_{T}$ can be estimated by Equations (16). The reference value of the boost chopper is given by

$$
V_{\text {ref }}^{*}=I_{T} R_{M} \text {. }
$$

The PI controller uses to track the reference and reduce the error, which is obtained by subtracting $V_{T}$ from $V^{*}{ }_{r e f}$ close to zero. The duty ratio $D$ and $D^{\prime}$ are calculated by the output value $v_{C}$ of the PI controller. 
Thus the MPPT control method in this paper can be estimated the output of the synchronous generator with only current sensor by analyzing the boost chopper using state space averaging method. Hence, the voltage of the maximum power point can be decided without calculation of the power.

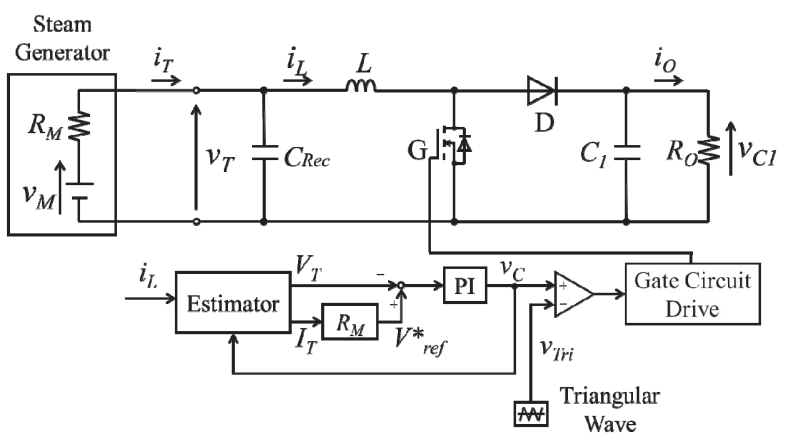

Fig. 9. A circuit diagram with the proposed MPPT control method

\section{Simulation Results}

Digital computer simulations using PLECS software were implemented to confirm the validity and viability of the proposed charging system.

\subsection{Simulation results in only generating period}

Fig. 10 shows the simulation result when the steam generator speed was $1200 \mathrm{rpm} . V_{T}$ is the estimated terminal voltage, $v_{T}$ is the terminal voltage, $p$ is the generated power, $v_{C 1}$ is the DC link voltage and $v_{B}$ is the battery voltage. $V_{T}$ corresponded to $v_{T}$ by using the estimator in the steady state. The generated power was $127.3 \mathrm{~W}$ which is generally similar to the results of Fig.1. The DC link voltage $v_{C 1}$ was $75 \mathrm{~V}$ and the voltage of the battery $v_{B}$ was $13 \mathrm{~V}$. All voltages tracked the reference voltage.

Fig. 11 shows the simulation results on V-P for each rotation speed. In Fig.10, the black points plotted the generated power point on the simulation results with the proposed MPPT control. The average error for the maximum power point voltage between the simulation results and the V-P characteristic was within $0.9 \%$. The results reveal that the proposed MPPT controller can track the maximum power point.

\subsection{Simulation results in all modes}

Digital computer simulation with both the generating and intermittent modes was implemented in this section. Table 1 indicates a short model pattern of the steam discharge for the simulation. The period A, C and D are the generating mode. The period $\mathrm{B}$ and $\mathrm{E}$ are the intermittent mode.

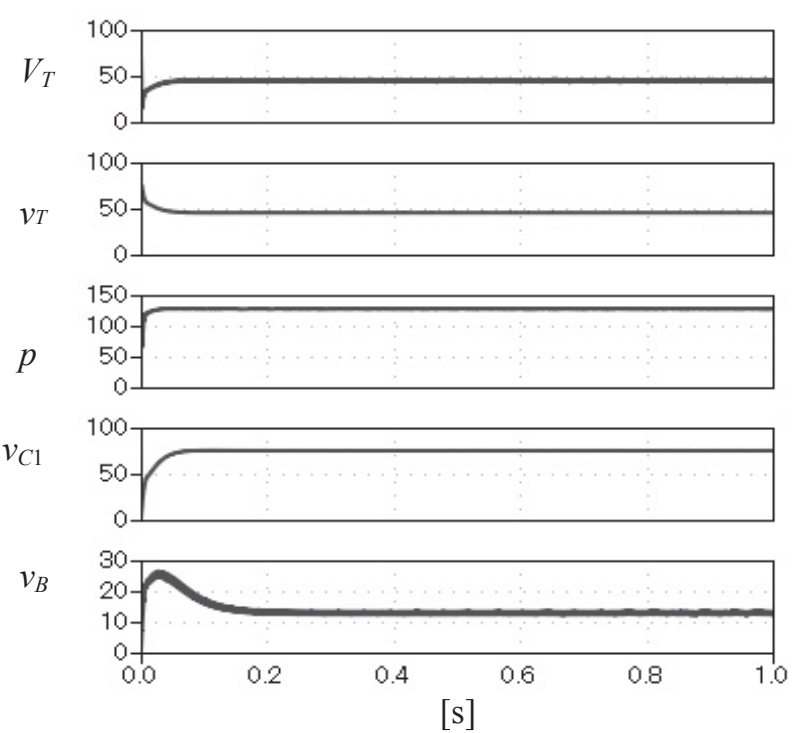

Fig. 10. Simulation results with the proposed MPPT control method when the steam generator speed was $1200 \mathrm{rpm}$.

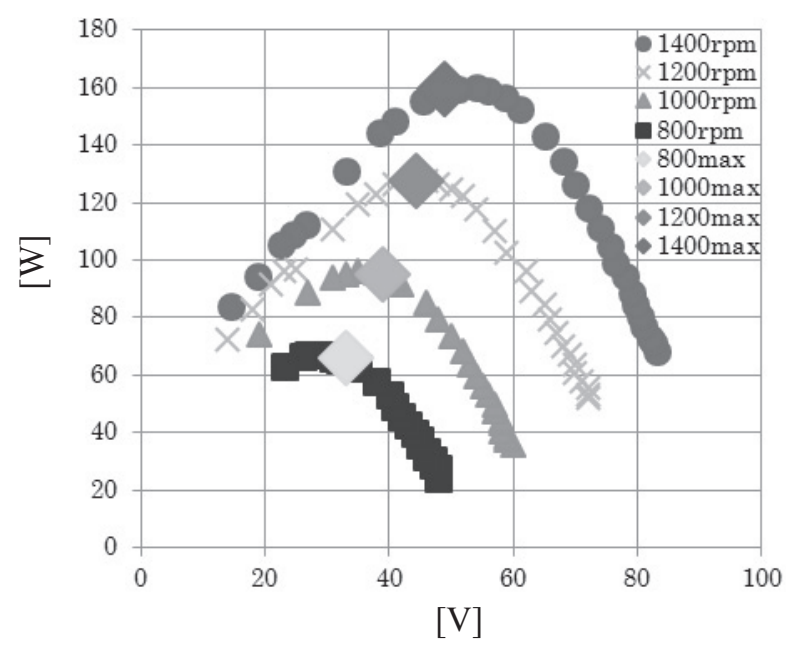

Fig. 11. Simulation results on V-P for each rotation speed.

Table 1 A pattern of the steam discharge.

\begin{tabular}{|c|c|c|}
\hline Period & Time $[\mathrm{s}]$ & $\begin{array}{c}\text { the steam generator } \\
\text { speed [rpm] }\end{array}$ \\
\hline A & $0 \sim 0.2$ & 800 \\
\hline B & $0.2 \sim 0.4$ & 10 \\
\hline C & $0.4 \sim 0.6$ & 1000 \\
\hline D & $0.6 \sim 0.8$ & 1200 \\
\hline E & $0.8 \sim 1.0$ & 10 \\
\hline
\end{tabular}

Fig. 12 shows the simulation result with all modes. During the generating mode, the generated power is similar to the results of Fig. 1. The DC link voltage $v_{C 1}$ was $75 \mathrm{~V}$. The capacitor $C_{E D L C}$ were charged from the surplus power using a bi-directional DC/DC converter in the generating mode. In the intermittent mode, the capacitor $C_{E D L C}$ was discharged the electricity because 
the bi-directional DC/DC converter acts as a boost chopper for charging the battery. The voltage of the battery $v_{B}$ were $13 \mathrm{~V}$ during all modes. Therefore the battery was charged constantly. The simulation results reveal that the propose charging system is the validity.

\section{Conclusion}

This paper proposed a battery charging system for intermittent generation from a synchronous generator with novel MPPT control method.

Digital computer simulation revealed that the proposed MPPT controller with only a single sensor could track the maximum power point. From the simulation results, the average error for the maximum power point voltage between the simulation results and the V-P characteristic was within $0.9 \%$. The proposed charging system was able to charge the battery constantly. These results revealed the proposed battery charging system is practicable.
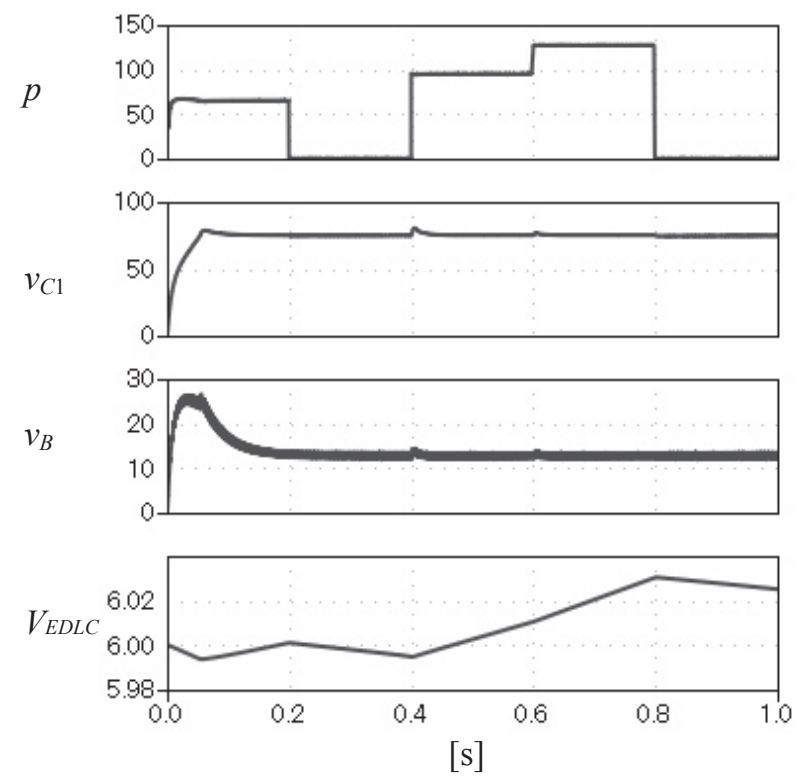

Fig. 12. Simulation result when the steam generator worked in the intermittent generation.

\section{References}

[1] Y. Shirai and M. A. Hassan, "Towards Zero Emission from Palm Oil Industry in Malaysia," Journal of Environmental Biotechnology, Vol. 9, No.1, pp.3-10, 2009.

[2] C. Aravind Vaithilingam, Norhisam Misron, Ishak Aris, Mohammad H. Marhaban and Masami Nirei, "ELECTROMAGNETIC DESIGN AND FEM ANALYSIS OF A NOVELDUAL-AIR-GAP RELUCTANCE MACHINE," Progress In Electromagnetics Research, Vol.140, 2013.

[3] M. Norhisam, S. Ridzuan, R. N. Firdaus, C. V. Aravind, H. Wakiwaka and M. Nirei, "COMPARATIVE
EVALUATION ON POWER-SPEED DENSITY OF PORTABLE PERMANENT MAGNET GENERATORS FOR AGRICULTURAL APPLICATION," Progress In Electromagnetics Research, Vol.129, pp.345-363, 2012.

[4] A. Sattar, A. Al Durra, C. Caruana, S. M. Muyeen, J. Tamura, "Real-Time Implementation of BESS to Smooth the Output Power Fluctuation of Variable Speed Wind Turbine Generator," IEEJ Journal of Industry Applications, Vol.3, No.3, pp.198-205, 2014

[5] Y. Zhu, M. Cheng, W. Hua and W. Wang, "A Novel Maximum Power Point Tracking Control for Permanent Magnet Direct Drive Wind Energy Conversion Systems," Energies, pp.1398-1412, 2012.

[6] K. Takahashi, E. Hiraki and T. Tanaka, ” Energy-Saving Effect of the Add-on Energy Recovery System for Electric Motor Drive Systems in the Injection Molding Machine," IEEJ Trians. IA, Vol.130, No.5, pp.714-715, 2010, (in Japanese).

[7] K. Harada, T. Ninomiya, and B. Gu, "The fundamentals of switched-mode converters," Corona Publ., pp.41-51, 1992.

[8] H. Yamada, K. Kimura and T. Hanamoto, "A Novel MPPT Control Method of Thermoelectric Power Generation with Single Sensor," Appl. Sci. 2013, 3, pp.545-558, 2013. 